\title{
Fragmentations of Protonated Benzaldehydes via Intermediate Ion/Molecule Complexes $\dagger$
}

\author{
U. Filges and Hans-Fr. Grützmacher \\ Fakultät für Chemie, Universität Bielefeld, Universitätsstraße 25, D-4800 Bielefeld 1, West Germany
}

\begin{abstract}
Ions $a_{p}$ and $a_{m}$ corresponding to protonated $p$ - and $m$-methoxymethylbenzaldehydes have been generated in a mass spectrometer by electron impact fragmentation of the correspondingly substituted 1-phenylethanols (1 and 2). Metastable ions $a_{p}$ and $a_{m}$ (2nd FFR of a VG-ZAB-2F mass spectrometer) react by elimination of $\mathrm{CH}_{3} \mathrm{OH}$, loss of $\mathrm{HCOOCH}_{3}$, formation of ions $\mathrm{CH}_{2}=\mathrm{OCH}_{3}$ and to a small extent by loss of $\mathrm{CH}_{2} \mathrm{O}$ and $\mathrm{CH}_{3} \mathrm{OCH}_{3}$, respectively. The mechanisms of these reactions have been studied by extensive D-labelling, and it is shown that these fragmentations are initiated by a transfer of the proton located originally at the carbonyl group onto the aromatic ring. The formation of ions $\mathrm{CH}_{2}=\stackrel{\mathrm{O}}{\mathrm{O}} \mathrm{CH}_{3}$ and the loss of $\mathrm{CH}_{3} \mathrm{OH}$ occurs via $\pi$-and $\sigma$-complexes. The elimination of $\mathrm{HCOOCH}_{3}$ from ions $a_{p}$ and $a_{m}$ corresponds to a functional group interaction between distal side chains and occurs via intermediate ion/molecule complexes formed by a protolytic cleavage of the formyl group. The loss of $\mathrm{CH}_{2} \mathrm{O}$ and $\mathrm{CH}_{3} \mathrm{OCH}_{3}$ proceeds also by intermediate ion/molecule complexes which are generated by a protolytic cleavage of the methoxymethyl side chain in ions $a_{p}$ and $a_{m}$.
\end{abstract}

Ion/neutral complexes are intermediates during the unimolecular fragmentation reactions of isolated ions in the gas phase. This has first been noted by $P$. Longevialle and coworkers ${ }^{1}$ during a study of the mass spectra of certain diamino steroids and related substances. More recently, T. H. Morton has shown in a review ${ }^{2}$ that intermediate ion/neutral complexes are much more important for mass spectrometric fragmentations than hitherto expected. In fact, an ion/neutral complex in which the ion and the departing neutral fragment interact by ion/dipole and ion/induced dipole forces has to be an intermediate for every fragmentation reaction. This follows from the current theories of ion/molecule reactions ${ }^{3}$ which assume the formation of an encounter complex via a loose transition state as a first reaction step. The reaction comes to completion within the complex by crossing an intrinsic energy barrier which corresponds to the 'chemical' transition state of bond formation and bond rearrangements. The unimolecular fragmentation of a large ion corresponds to the reversal of an association reaction of a smaller ion and the neutral fragment. Thus, by the principle of microscopic reversibility, a loosely bound ion/neutral complex is passed during the fragmentation reaction after the 'chemical' transition state. However, this second transition state for the dissociation of the ion/neutral complex is a very loose one and, thus, does not correspond to a 'bottle neck'3 for the total reaction. Hence, the intermediate ion/neutral complex is not of major importance for the rate of the fragmentation of ions with high internal energies, which react in the ion source of a mass spectrometer, and these complexes have escaped the attention of

$\dagger$ Dedicated to Prof. Dr. H.-D. Beckey on the occasion of his 65 th birthday. mass spectroscopists for a long time. In the study of the gas phase reactions of ions with low internal energies the formation of an intermediate ion/neutral complex cannot be neglected. This is clearly shown by the results represented in the literature..$^{1,2}$

A detailed study of the properties of ion/neutral complexes as intermediates of unimolecular ionic reactions is important for two reasons. Firstly, the ion/neutral complex may be prepared by a unimolecular dissociation with less internal energy than by a bimolecular reaction, because in the latter case the relative kinetic energy and the attractive forces between the particles are transformed into internal energy. Therefore, the ionic and the neutral fragment may stick together rather closely in a unimolecularly formed complex for a long time giving rise to 'intramolecular' reactions with special 'proximity effects' which are of interest for the theory of ion/neutral reactions. With respect to these effects the intermediate ion/neutral complex of a unimolecular dissociation of an ion may be of the same importance for the outcome of the reaction as the primary formation of intimate ion pairs in the course of a solvolytic process, ${ }^{2,4}$ and something like an internal return' has to be expected also for the intermediate ion/neutral complexes. This may give rise to intramolecular isomerization reactions. Indeed, the rearrangements of 'incipient' carbenium ions during a mass spectrometric fragmentation are well known.,5 Secondly, the modern mass spectrometric techniques for the investigation of metastable ions ${ }^{6}$ as well as ion trap chemistry ${ }^{7}$ and Fourier transform-ion cyclotron resonance (FT-ICR) spectroscopy ${ }^{8}$ all deal with the reaction of long-lived ions with low internal energies which may react via intermediate ion/neutral complexes. For the analytical applications of these techniques (tandem mass spectrometry, MS/MS ${ }^{9}$ ) one 
has to know much more about the effects of these complexes on the course of mass spectrometric fragmentations than hitherto is known.

Even-electron ions which are formed with low internal energies by chemical ionization (CI) appear especially prone to the formation of intermediate ion/neutral complexes, probably because of a facile protolytic bond cleavage. Thus, the CI-mass spectra and especially the metastable ion (MI) spectra and collisional activation (CA) spectra of ions formed by CI show rather surprising fragmentations which can be related to the original ion structures only with difficulty. Even-electron ions which correspond to protonated molecules can also be formed under EI-conditions by a fragmentation reaction. Recently, we have adopted this technique for a study of site-specifically protonated aromatic hydrocarbons. ${ }^{10}$ This paper is the first one of a series in which we report the results of a study of the unimolecular gas phase reactions of protonated aromatic carbonyl compounds. Again, these even-electron ions are generated by EI-fragmentations with the proton initially at the carbonyl oxygen. It will be shown that the migration of this proton to the aromatic moiety starts a series of reactions which can be explained only by intermediate ion/neutral complexes.

\section{RESULTS AND DISCUSSION}

Figures 1 and 2 show the $70 \mathrm{eV}$ EI-mass spectra of 1-(4-methoxymethylphenyl) ethanol, 1 and 1-(3methoxymethylphenyl)-ethanol, 2 , respectively. The fragmentation of the molecular ions starts by $\alpha$-cleavage at the benzylic position and loss of $\mathrm{CH}_{3} \cdot$ to give rise to ions $a_{p}$ (from 1) and $a_{m}$ (from 2), $m / z 151$, with the structures of protonated benzaldehydes. The MI-spectra of the molecular ions $[1]^{+\cdot}$ and $[2]^{+\cdot}$ contain a peak for this reaction besides a large signal for loss of $\mathrm{CH}_{3} \mathrm{OH}$, indicating that the formation of $a_{p}$ and $a_{m}$ is also an energetically favoured process as expected. Furthermore, the spectra of deuterated derivatives (see below) show that only the $\mathrm{CH}_{3}$-group of the hydroxyethyl side chain is lost.

The abundant ions $m / z 45$ and 43 , respectively, are formed from the methoxymethyl side chain and the hydroxyethyl side chain, as indicated by the

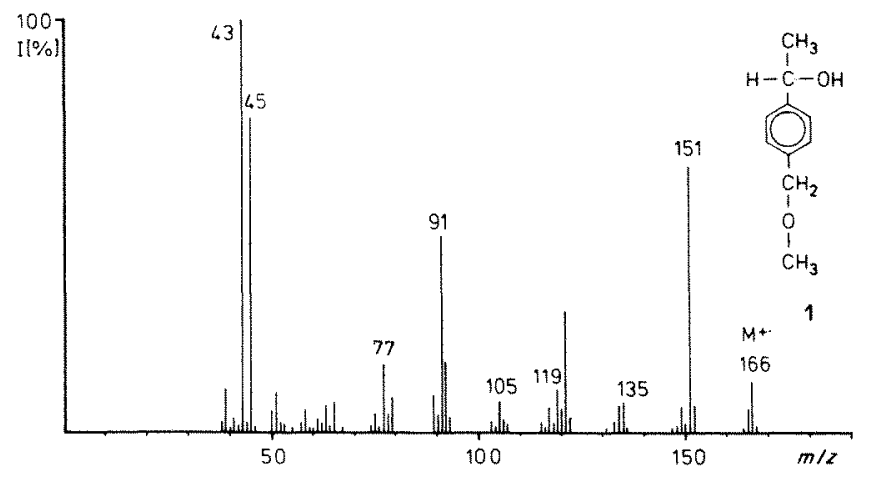

Figure 1. $70 \mathrm{eV} \mathrm{El-mass} \mathrm{spectrum} \mathrm{of} \mathrm{1-(4-methoxymethyl-}$ phenyl)-ethanol, 1.

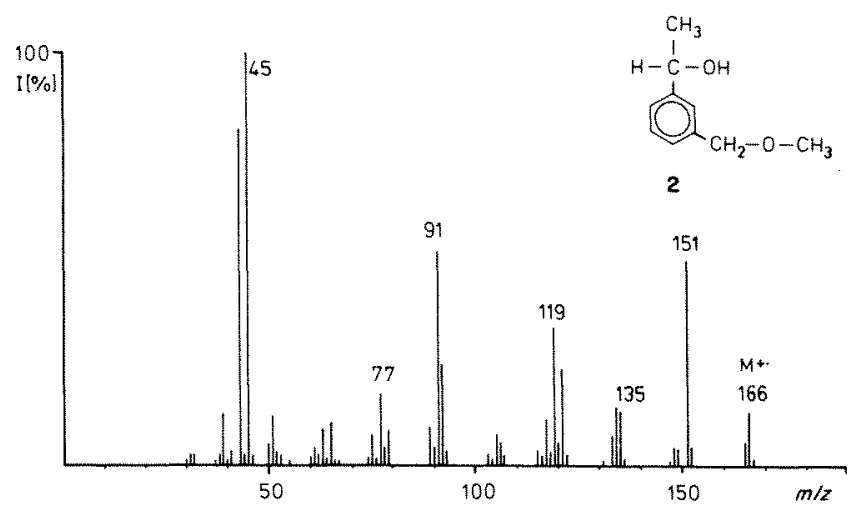

Figure 2. $70 \mathrm{eV}$ El-mass spectrum of 1-(3-methoxymethylphenyl)-ethanol, 2.

appropriate mass shifts in the EI-mass spectra of deuterated analogues. Note the peaks of the $\mathrm{C}_{7} \mathrm{H}_{7}{ }^{+}$ ions, $m / z 91$, which have to arise from a fragmentation in both side chains of 1 and 2, and of ions $m / z 119$, which correspond to ions $\left(a_{p}-\mathrm{CH}_{3} \mathrm{OH}\right)$ and $\left(a_{m}-\mathrm{CH}_{3} \mathrm{OH}\right)$. The formations of the ions $m / z 45,91$ and 119 can be easily explained by a migration of the proton at the carbonyl group of $a_{p}$ and $a_{m}$ to and across the benzene ring. Analogous fragmentations have been observed in the EI-mass spectra of other 1-phenylethanols carrying a variety of substituents at the phenyl group. ${ }^{11}$ Thus, fragmentations induced by proton migration from a protonated carbonyl group to a benzene ring appear to be a general phenomenon in this class of compounds.

The MI spectra (Fig. 3 and 4) obtained by the mass-analysed ion kinetic energy (MIKE)-technique ${ }^{6}$ of ions $a_{p}$ and $a_{m}$ prove that these ions are indeed the precursors of the ions $m / z 119,91$ and 45 . Two additional small peaks are seen at $m / z 121\left(a-\mathrm{CH}_{2} \mathrm{O}\right)$ and at $m / z 105\left(a-\mathrm{CH}_{3} \mathrm{OCH}_{3}\right)$. The mechanisms of these five fragmentation reactions have been studied further in the MI-spectra of deuterated analogues of ions $a$ derived from the labelled derivatives shown in Scheme 1 . The results are presented in Table 1 and the reactions of ion $a$ will be discussed separately.

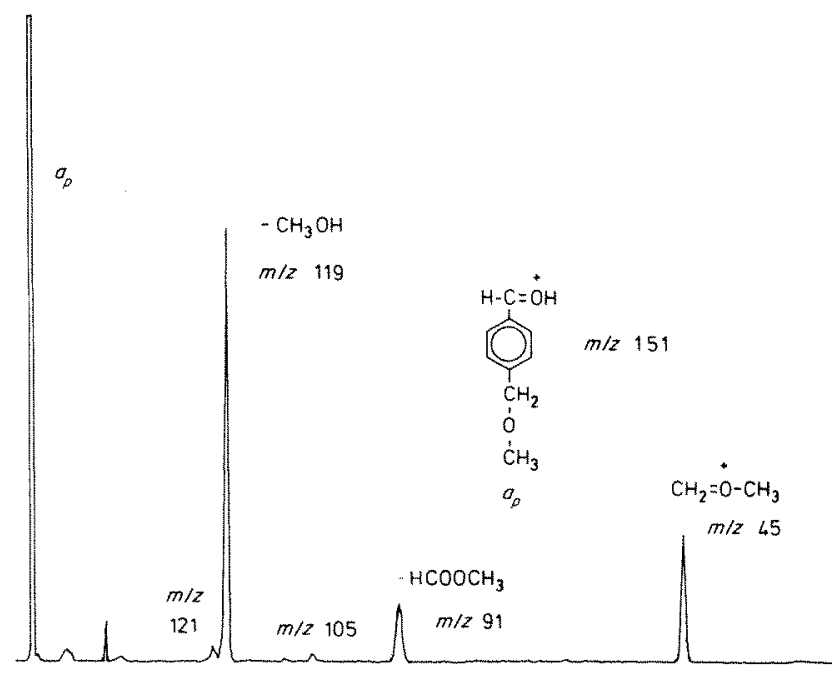

Figure 3. Ml-spectrum of ion $a_{p}$ from $1(70 \mathrm{eV})$. 


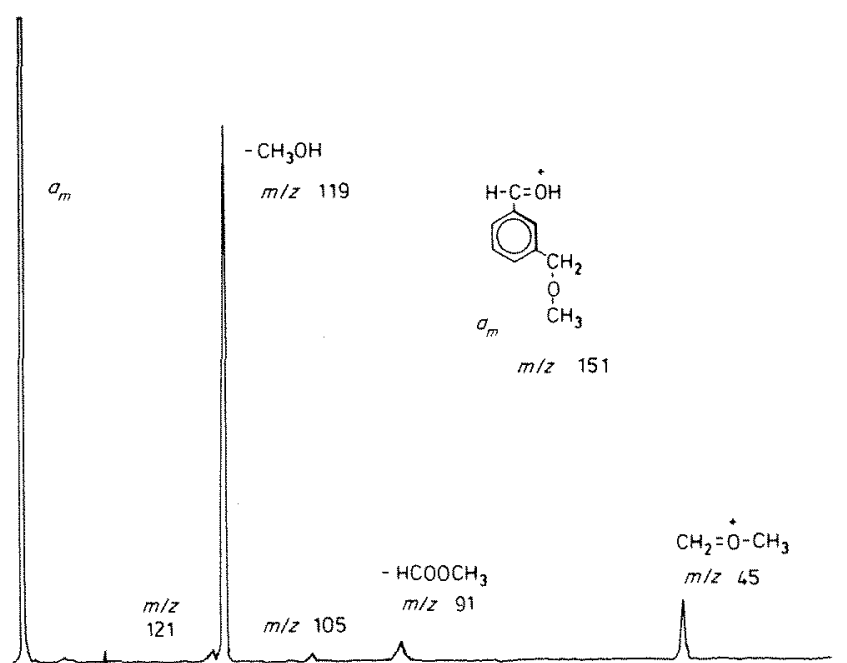

Figure 4. MI-spectrum of ion $a_{m}$ from $2(70 \mathrm{eV})$.

\section{$\mathrm{CH}_{2}=\stackrel{+}{\mathrm{O}} \mathrm{CH}_{3}$}

The ions $m / z 45$ are completely shifted to $m / z 47$ and 48 , respectively, in the MI-spectra of ions $a_{p}$ derived from 1c, Id, and 1e, and stay at $m / z 45$ in the case of $\mathbf{1 a}, \mathbf{1 b}, \mathbf{2 a}$, and $\mathbf{2 b}$. This clearly shows that the methoxymethyl side chain of $a_{p}$ is lost without any exchange of its $\mathrm{H}$-atoms, and this makes a preceding skeletal rearrangement between ion $a$ and their tropylium counterparts very unlikely. Thus, the formation of $\mathrm{CH}_{2}=\mathrm{OCH}_{3}$ can be described by reaction (1):

(1)

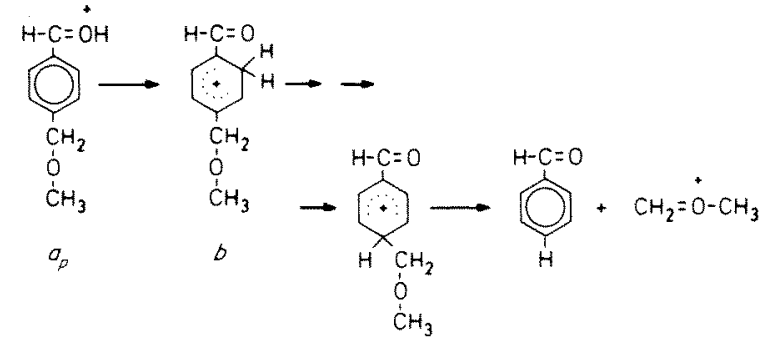

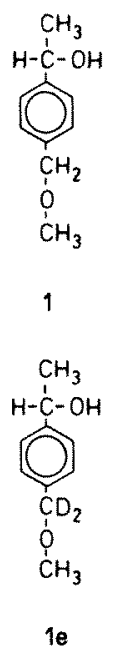
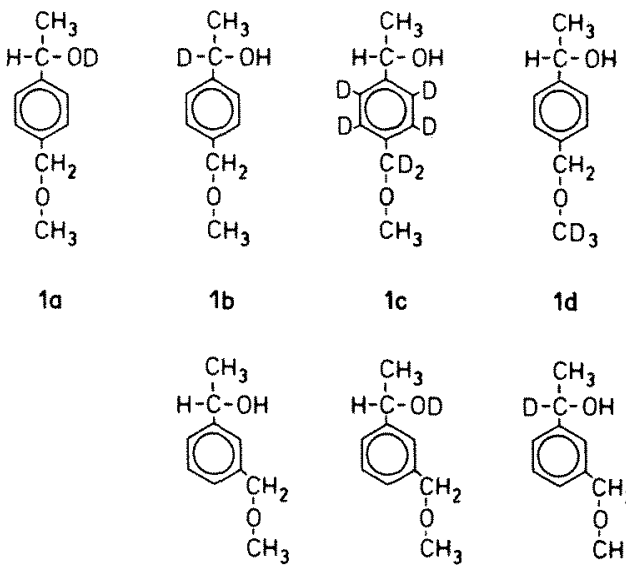

id

$\mathrm{CH}_{3}$<smiles>[2H]C(C)(O)c1cccc(COC)c1</smiles>

2

$2 a$

$2 b$

$$
\mathrm{OCH}-\mathrm{C}_{6} \mathrm{H}_{4}-\mathrm{CH}_{2}^{+},\left(a-\mathrm{CH}_{3} \mathrm{OH}\right)
$$

The loss of $\mathrm{CH}_{3} \mathrm{OH}$ from ions $a$ is the most favoured fragmentation route, especially in the case of $a_{m}$. Elimination of $\mathrm{CD}_{3} \mathrm{OH}$ from $a$ formed by $1 d$ indicates loss of the methoxy group as expected. Note that no $\mathrm{CH}_{3} \mathrm{OD}$ is lost if deuterated ions $a$ are generated from $\mathbf{1 b}$ and $\mathbf{2 b}$ which proves that only the proton at the carbonyl group migrates to the benzene ring according to reaction (2), until eventually the methoxy group is protonated in $d$ :

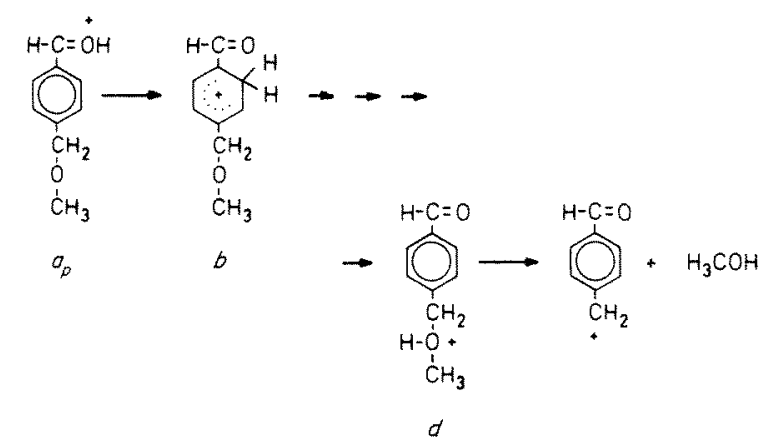

Table 1. MIKE-spectra $(70 \mathrm{eV})$ of ions $a_{p}, a_{m}$, and their deuterated analogues (values given in parenthesis represent deuterium-distribution on neutral fragments)

\begin{tabular}{|c|c|c|c|c|c|c|c|c|c|}
\hline & & & & & & & $a_{p} \uparrow$ & & \\
\hline & 1 & 1a & 1b & 1c & 1d & 1e & 2 & $2 \mathbf{a}$ & $\mathbf{2 b}$ \\
\hline$-\mathrm{CH}_{2} \mathrm{O}$ & 1 & $2(100 \%)$ & $2(100 \%)$ & - & $3(100 \%)$ & - & 1 & $1(100 \%)$ & $1(100 \%)$ \\
\hline$-\mathrm{CD}_{2} \mathrm{O}$ & - & - & - & $2(100 \%)$ & - & $2(100 \%)$ & - & - & - \\
\hline$-\mathrm{CH}_{3} \mathrm{OH}$ & 69 & $46(74 \%)$ & $70(100 \%)$ & $37(56 \%)$ & - & $59(100 \%)$ & 82 & $20(23 \%)$ & $85(100 \%)$ \\
\hline$-\mathrm{CH}_{3} \mathrm{OD}$ & - & $16(26 \%)$ & - & $29(54 \%)$ & - & - & - & $68(77 \%)$ & - \\
\hline$-\mathrm{CD}_{3} \mathrm{OH}$ & - & - & - & - & $64(100 \%)$ & - & - & 一 & - \\
\hline$-\mathrm{CH}_{3} \mathrm{OCH}_{3}$ & 1 & $1(100 \%)$ & - & - & - & - & 1 & $1(100 \%)$ & 一 \\
\hline$-\mathrm{CH}_{2} \mathrm{DOCH}_{3}$ & - & - & $1(100 \%)$ & - & - & - & - & - & $1(100 \%)$ \\
\hline$-\mathrm{CHD}_{2} \mathrm{OCH}_{3}$ & - & - & - & $2(100 \%)$ & - & $1(100 \%)$ & - & - & - \\
\hline$-\mathrm{CD}_{3} \mathrm{OCH}_{3}$ & - & - & - & - & $2(100 \%)$ & - & - & - & - \\
\hline$-\mathrm{HCOOCH}_{3}$ & 8 & $10(100 \%)$ & $2.4(20 \%)$ & $9.4(85 \%)$ & - & $10(100 \%)$ & 2 & $3(100 \%)$ & $1.3(33 \%)$ \\
\hline$-\mathrm{DCOOCH}_{3}$ & - & - & $9.6(80 \%)$ & $1.6(15 \%)$ & - & - & - & - & $2.7(67 \%)$ \\
\hline$-\mathrm{HCOOCD}_{3}$ & - & - & - & - & $8(100 \%)$ & - & - & - & - \\
\hline${ }^{+} \mathrm{CH}_{2} \mathrm{OCH}_{3}$ & 20 & $24(100 \%)$ & $15(100 \%)$ & - & - & - & 13 & $7(100 \%)$ & $10(100 \%)$ \\
\hline${ }^{+} \mathrm{CD}_{2} \mathrm{OCH}_{3}$ & - & - & - & $22(100 \%)$ & - & $28(100 \%)$ & - & - & - \\
\hline${ }^{+} \mathrm{CH}_{2} \mathrm{OCD}_{3}$ & - & - & - & - & $23(100 \%)$ & - & - & - & - \\
\hline
\end{tabular}


During the 'ring walk' of the proton from the carbonyl group to the methoxy group the intermediate formation of $\sigma$-complexes $b$ and $c$ is expected and, hence, an exchange between the proton originally at the carbonyl group and the hydrogen atoms at the benzene ring. This exchange can not be observed in the case of reaction (1) but should give rise to loss of $\mathrm{CH}_{3} \mathrm{OH}$ and $\mathrm{CH}_{3} \mathrm{OD}$ from ions $a$ of 1a, $1 \mathrm{c}$, and $2 \mathrm{a}$ via reaction (2). Indeed, this is observed (Table 1) but the $\mathrm{H} / \mathrm{D}$-exchange is far from its statistical value, and at the moment the amount of the exchange observed is not understood at all. No loss of $\mathrm{CH}_{3} \mathrm{OD}$ is observed for $a_{p}$ derived from $1 \mathrm{e}$ which excludes ring enlargement to a tropylium structure prior to decomposition.

The ions $a_{m}$ derived from 2a prefer loss of $\mathrm{CH}_{3} \mathrm{OD}$ in spite of the expected mixing of one $\mathrm{D}$ and four $\mathrm{H}$. The distance between the protonated carboxy group and the methoxy group at the meta position is too large for a transfer of $\mathrm{H}^{+}$through space. Thus, the migration of the $\mathrm{D}^{+}$across the benzene ring probably occurs mostly by an intermediate $\pi$-complex (reaction (3)) without any exchange.

(3)
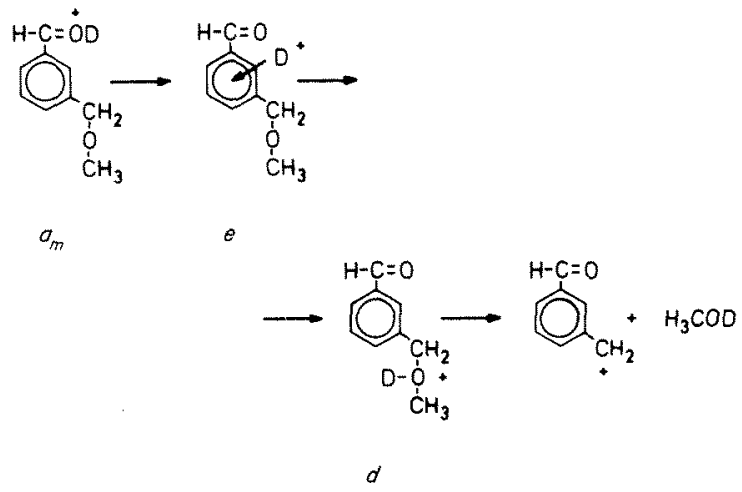

In contrast to this, both deuterated ions $a_{p}$ derived from 1a and 1c eliminate $\mathrm{CH}_{3} \mathrm{OH}$ over $\mathrm{CH}_{3} \mathrm{OD}$ by similar amounts, although the H/D-ratio is $4 / 1$ for 1a, and $1 / 4$ for $1 \mathrm{c}$, if the D-atoms at the methoxymethyl substituent are neglected. A ratio $-\mathrm{CH}_{3} \mathrm{OH} /-$ $\mathrm{CH}_{3} \mathrm{OD}=53 \%: 47 \%$ has been observed for the reaction of $a$ from $1 \mathrm{c}$ in the first field free region of the VG-ZAB-2F mass spectrometer, which is close to the value $56 \%: 46 \%$ for decompositions in the second field free region. The reactions of ions $a$ derived from 1c have also been studied in a Research Ion Trap ${ }^{12}$ which allows for reaction times from several milliseconds to several seconds. The result ($\mathrm{CH}_{3} \mathrm{OH} /-\mathrm{CH}_{3} \mathrm{OD}=58: 42$ ) clearly shows that the amount of $\mathrm{H} / \mathrm{D}$-exchange in $a_{p}$ is nearly independent of the ion lifetime and that the incomplete $\mathrm{H} / \mathrm{D}$-scrambling is not due to one exchange process which has not come to completion in the second field free region of the VG-ZAB-2F mass spectrometer. ${ }^{13}$ Thus, it appears that different mechanisms, i.e. intermediate $\sigma$ - and $\pi$-complexes, with different isotope effects and different orientation effects of the substituents at the benzene ring contribute to the $\mathrm{CH}_{3} \mathrm{OH}$-elimination. Similar effects of the H/Dexchange have been observed during the reactions of other deuterated aromatic compounds, ${ }^{14}$ but many more experimental results have to be collected to explain these effects.

\section{$\mathrm{C}_{7} \mathrm{H}_{7}^{+},\left(a-\mathrm{HCOOCH}_{3}\right)$}

Although the formation of $\mathrm{C}_{7} \mathrm{H}_{7}{ }^{+}$ions, $m / z$ 91, is not an abundant process of metastable ions $a$ (see Fig. 3 and Fig. 4) the loss of a fragment (or fragments) of $60 u$ is an interesting reaction. ${ }^{15}$ The mass shifts observed for this process in the MI-spectra of deuterated $a$ (Table 1) show that $\mathrm{HCOOCH}_{3}$ or $\left(\mathrm{CO}+\mathrm{HOCH}_{3}\right)$ is lost. Three mechanisms can be envisaged for this process:

i) Fast consecutive reactions $a \rightarrow(a-\mathrm{CO}) \rightarrow$ $\left(a-\mathrm{CO}-\mathrm{CH}_{3} \mathrm{OH}\right)$ or $a \rightarrow\left(a-\mathrm{CH}_{3} \mathrm{OH}\right) \rightarrow$ $\left(a-\mathrm{CH}_{3} \mathrm{OH}-\mathrm{CO}\right)$. No loss of $\mathrm{CO}$ is observed in the MI-spectra of $a_{p}$ and $a_{m}$, and this leaves only the second reaction sequence (4) as a likely mechanism.

(4)

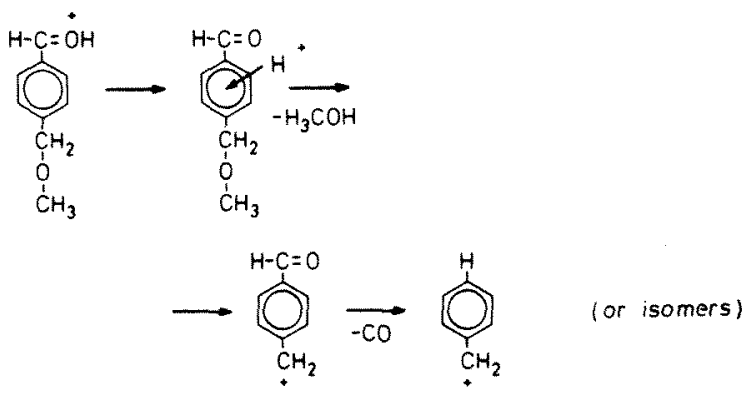

However, in this case the H/D-distribution of the ions $\left(a-\mathrm{CH}_{3} \mathrm{O}(\mathrm{H}, \mathrm{D})\right)$ in the case of $1 \mathrm{a}-1 \mathrm{e}$, and $\mathbf{2 a}, \mathbf{2 b}$ should be retained in the ions $\left(a-\mathrm{CH}_{3} \mathrm{O}(\mathrm{H}, \mathrm{D})-\mathrm{CO}\right)$. This is clearly not the case (Table 1 ). Only the ions $a$ derived from 1d lose $\mathrm{CD}_{3} \mathrm{OH}$ as well as $\left(\mathrm{CD}_{3} \mathrm{OH}+\right.$ $\mathrm{CO}$ ). In the case of $1 \mathrm{a}$ and $2 \mathrm{a}$ where $a$ loses $\mathrm{CH}_{3} \mathrm{OH}$ and $\mathrm{CH}_{3} \mathrm{OD}$, only loss of $\left(\mathrm{CH}_{3} \mathrm{OH}+\mathrm{CO}\right)$ is observed whereas $a$ from $\mathbf{1 b}$ and $\mathbf{2 b}$ eliminates only $\mathrm{CH}_{3} \mathrm{OH}$ but loses $\left(\mathrm{CH}_{3} \mathrm{OH}+\mathrm{CO}\right)$ or $\left(\mathrm{CH}_{3} \mathrm{OD}+\mathrm{CO}\right)$. The contradictory behaviour excludes reaction (4) as the mechanism, and the $60 u$ are lost as the single entity $\mathrm{HCOOCH}_{3}$ from $a$.

ii) The elimination of a molecule of methyl formate, $\mathrm{HCOOCH}_{3}$, from $a$ may occur by an ortho-effect even in the case of the para- and meta-substituted ions $a_{p}$ and $a_{m}$, if an isomerization into the ortho-derivative $a_{0}$ takes place by a benzyl ion/tropylium ion ring expansion/ring contraction prior to decomposition (reaction (5)).

(5)

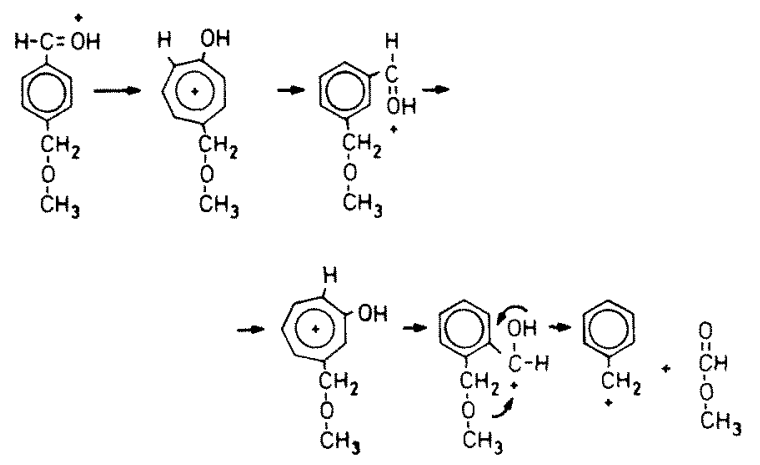


However, there are several experimental observations which do not agree with this 'conventional' fragmentation mechanism. Firstly, the skeletal rearrangement of $a$ will distribute a D-atom at the original protonated aldehyde group of $a$ over all positions of the benzene ring, and vice versa. This is not observed for ions $a_{p}$ and $a_{m}$ derived from $\mathbf{1 b}, \mathbf{1 c}$, and $\mathbf{2 b}$ (Table 1) although some $H / D$-exchange between the formyl group and the phenylene group occurs. Secondly, it is known that $\alpha$-hydroxybenzyl ions and hydroxytropylium ions are stable species which do not interconvert easily. ${ }^{16}$ Thirdly, it will be shown in forthcoming papers that the elimination of $\mathrm{HCOOCH}_{3}$ from methoxymethylsubstituted and protonated aromatic aldehydes is still observed when the aromatic systems make a skeletal rearrangement of the ions very unlikely.

iii) The experimental observations are best explained by assuming an intermediate ion/neutral ether molecule, which arises from $a$ by migration of the proton of the protonated aldehyde group into the ipso-position of the benzene ring (complex $f$ ) with a subsequent protolytic bond cleavage (reaction (6)).
(6)

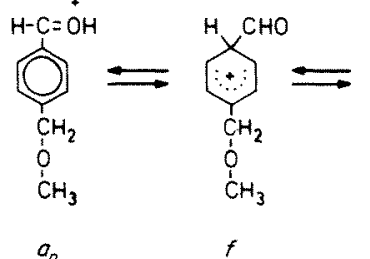

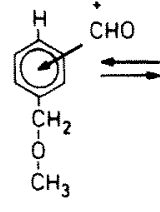

$g$ complex $g$ between a formyl ion and a benzylmethyl

Interestingly, one observes a certain amount of $\mathrm{H} / \mathrm{D}$-exchange between the formyl cation and the aromatic group. This indicates that some of the formyl cation/arene complexes. $g$ may isomerize to arenium ion/CO complexes $i$ and return to the former complexes before fragmentation (reaction (8)).
(8)

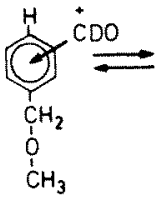

$g$

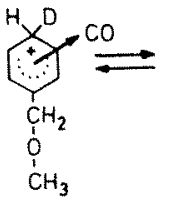

$i$

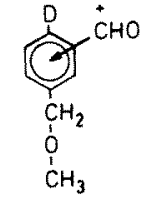

$g^{\prime}$
Protonated benzaldehyde and protonated tolylaldehydes decompose in the gas phase by loss of $\mathrm{CO},{ }^{11}$ in contrast to ions $a$, and this fragmentation proceeds via an intermediate arenium ion/CO complex (reaction (9)).
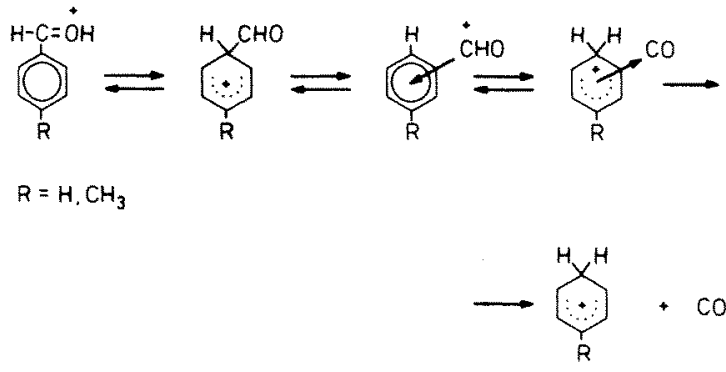

However, in this case one lacks an additional fragmentation reaction monitoring any $H / D$ exchange to see whether or not this reaction occurs with internal return within the ion/neutral complexes.

One can also think of a 'conventional ring walk' of the $\mathrm{CHO}^{+}$in $f$ by 1,2 -shifts along the benzene ring until it eventually reacts with the methoxy group. However, the electrostatic attraction between the formyl cation and the benzene nucleus being a $\pi$-base of considerable polarizability should be large. Assuming a distance of $3 \AA$ between $\mathrm{CHO}^{+}$and the centre of the benzene ring, the calculation of the ion/dipole forces by the classical formula (7) gives a stabilization energy $E_{\text {stab }}$ of $186 \mathrm{~kJ} \mathrm{~mol}^{-1}$. Thus, much excess energy can be stored in the complex $g$ before the dissociation limit is reached. In complex $g$ the formyl cation is rather free to move and will be directed towards the methoxy group by the dipole moments of the $\mathrm{C}-\mathrm{O}$ bonds until it combines with the $n$-base $\mathrm{CH}_{3} \mathrm{Q}-\mathrm{CH}_{2}-\mathrm{Ar}$ forming intermediate $h$. These directing and capturing effects of polar groups with electron lone pairs have also been observed in gas phase electrophilic aromatic substitutions. ${ }^{17}$

$$
\begin{aligned}
& V(r)=\frac{-\alpha q^{2}}{2 r^{4}}+\frac{-q \mu_{0}}{r^{2}} \\
& r=\text { mean distance } \\
& \alpha=\text { polarizability } \\
& \mu_{0}=\text { dipole moment of the } \\
& \quad \text { neutral component } \\
& q=\text { formal charge }
\end{aligned}
$$

\section{$\mathrm{C}_{6} \mathrm{H}_{5} \mathrm{CO}^{+}\left(a-\mathrm{CH}_{3} \mathrm{OCH}_{3}\right)$ and $\mathrm{C}_{6} \mathrm{H}_{5} \mathrm{CH}=\stackrel{\mathrm{OCH}}{3}$ $\left(a-\mathrm{CH}_{2} \mathrm{O}\right)$}

The crucial reaction step in forming the formyl cation/benzylmethylether complex $g$ is the protolytic bond cleavage in the ipso-protonated $\sigma$-complex $f$ (reaction (6)). An analogous $\sigma$-complex $c$ is formed in reaction (1) by migration of the proton into the ipso-position of the methoxymethyl substituent before the group eventually is lost. It is very likely therefore that a methoxymethyl cation/benzaldehyde complex $j$ is an intermediate of this reaction. The question arises whether one observes other fragmentations due to the intermediate $j$. Indeed, the losses of $\mathrm{CH}_{3} \mathrm{OCH}_{3}$ and $\mathrm{CH}_{2} \mathrm{O}$ from ions $a$ can be attributed to intermediate $j$. The reactions of deuterated $a$ prove (Table 1) that the dimethylether molecule is specifically formed from the intact $\mathrm{CH}_{3} \mathrm{OCH}_{2}$-substituent and the $\mathrm{H}$-atom at the CHO-group, while the $\mathrm{CH}_{2} \mathrm{O}$ stems from the - $\mathrm{CH}_{2} \mathrm{O}$-moiety of the $\mathrm{CH}_{3} \mathrm{OCH}_{2}$-substituent. The mechanisms for these fragmentations are given in reactions (10) and (11). from the formyl substituent by the ion $\mathrm{CH}_{2}=\mathrm{OCH}_{3}$ which can freely move in the complex $j$ and which is directed to the formyl group by the dipole moment of that group (complex $k$ ). Hydride abstractions are a typical reaction of $\mathrm{CH}_{2}=\mathrm{O}-\mathrm{CH}_{3}$ in bimolecular
Reaction (10) corresponds to a hydride abstraction 
<smiles>COC[C@H](C=O)c1ccc(C=O)cc1C=O</smiles>

(11)

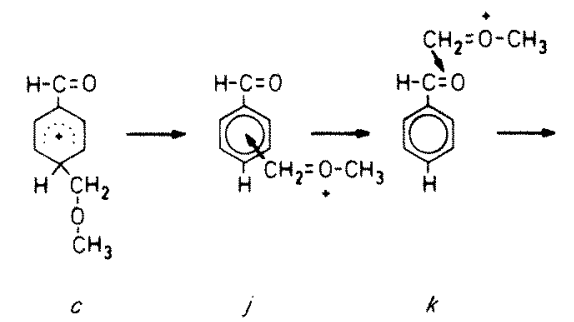

$$
\longrightarrow \overbrace{H}^{H-C=O}-\mathrm{CH}_{3}
$$

ion/molecule reactions. ${ }^{18}$ Similarly, reaction (11) can be envisaged as a methyl cation transfer from the $\mathrm{CH}_{2}=\mathrm{OCH}_{3}$ ion to the carbonyl group of the benzaldehyde molecule in complex $k$. Again, this is a reaction known from bimolecular ion/molecule reactions. ${ }^{18,19}$

\section{CI-EXPERIMENTS}

It is of interest to see whether ions of the structure $a_{p}$ and $a_{m}$ can also be generated by chemical ionization (CI) of para- and meta-methoxymethylbenzaldehyde 3 and 4 , respectively. The proton affinities (PA) of the functional groups in the side chains are probably similar $\left(\mathrm{PA}\left(\mathrm{R}_{2} \mathrm{CO}\right) \approx 840 \mathrm{~kJ} / \mathrm{mol} ; \mathrm{PA}\left(\mathrm{R}_{2} \mathrm{O}\right) \approx 850 \mathrm{~kJ} /\right.$ $\left.\mathrm{mol} ; \mathrm{PA}\left(\mathrm{C}_{6} \mathrm{H}_{6}\right)=759 \mathrm{~kJ} / \mathrm{mol}^{20}\right)$ and can be easily protonated by $\mathrm{CH}_{5}{ }^{+}$. The CA-spectra of protonated 3 and 4 are compared to that of ions $a_{p}$ and $a_{m}$ from 1 and 2, respectively, in Fig. 5 and Fig. 6. Each of the

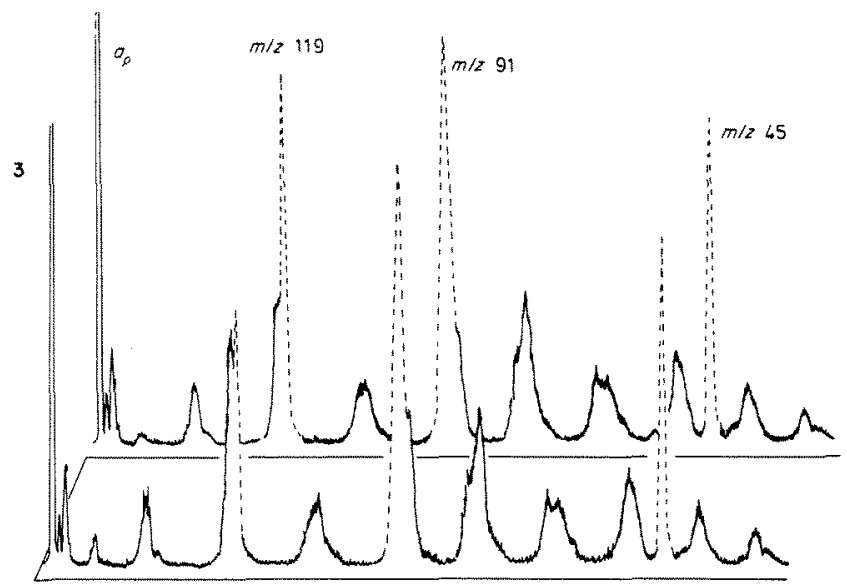

Figure 5. CA-spectra of $\mathrm{MH}^{+}$of p-methoxymethylbenzaldehyde, 3 and of $a_{p}$ (from 1).

pairs of CA-spectra is identical, proving identical structures (or mixtures of structures) for these ions.

The MIKE-spectra of the protonated benzaldehydes 3 and $\mathbf{4}$ are shown in Table 2. The main fragmentation routes are loss of $\mathrm{CH}_{3} \mathrm{OH}$, loss of $\mathrm{HCOOCH}_{3}$ and formation of $\mathrm{CH}_{2}=\mathrm{OCH}_{3}, m / z 45$, and are those observed for ions $a$ from 1 and 2 (Table 1). In addition to small peaks due to elimination of $\mathrm{CH}_{2} \mathrm{O}$ and of $\mathrm{CH}_{3} \mathrm{OCH}_{3}$, which have also been observed in the MIKE-spectra of $a$, small peaks due to loss of $\mathrm{CH}_{3}$ and $\mathrm{CO}$ are found. These peaks and the intensity differences observed in the MIKE-spectra of ions $a_{p}$ and $a_{m}$ generated by EI (Table 1) and CI (Table 2)

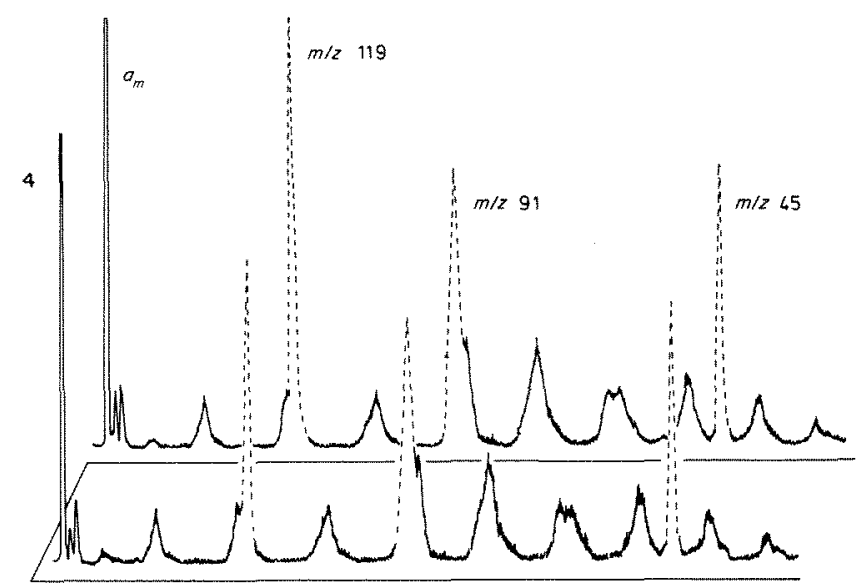

Figure 6. CA-spectra of $\mathrm{MH}^{+}$of $m$-methoxymethylbenzaldehyde 4 and of $a_{m}$ (from 2).

Table 2. MIKE-spectra of $\mathrm{MH}^{+}$of $p$ - and $m$-methoxymethylbenzaldehyde ( 3 and 4 )

\begin{tabular}{|c|c|c|c|c|}
\hline & \multicolumn{2}{|c|}{3} & \multicolumn{2}{|c|}{4} \\
\hline & $\mathrm{Cl}\left(\mathrm{CH}_{4}\right)$ & $\mathrm{Cl}\left(\mathrm{CD}_{4}\right)$ & $\mathrm{Cl}\left(\mathrm{CH}_{4}\right)$ & $\mathrm{Cl}\left(\mathrm{CD}_{4}\right)$ \\
\hline$-\mathrm{CH}_{3}$ & 7 & $<1$ & 5 & $<1$ \\
\hline$-\mathrm{CH}_{2} \mathrm{O}$ & 1 & 2 & 2 & 4 \\
\hline$-\mathrm{CH}_{3} \mathrm{OH}$ & 43 & $26(79 \%)$ & 68 & $15(23 \%)$ \\
\hline$-\mathrm{CH}_{3} \mathrm{OD}$ & - & $7(21 \%)$ & - & $52(77 \%)$ \\
\hline$-\mathrm{CH}_{3} \mathrm{OCH}_{3}$ & 1 & 1 & 1 & 1 \\
\hline$-\mathrm{HCOOCH}_{3}$ & 14 & 16 & 5 & 7 \\
\hline $\mathrm{CH}_{2}=\mathrm{O} \mathrm{CH}_{3}$ & 31 & 46 & 20 & 22 \\
\hline
\end{tabular}


can be attributed to differences of the internal energies. The MIKE-spectra of the deuteronated benzaldehydes generated by $\mathrm{CI}\left(\mathrm{CD}_{4}\right)$ (Table 2 ) shows peaks for the elimination of $\mathrm{CH}_{3} \mathrm{OH}$ and $\mathrm{CH}_{3} \mathrm{OD}$, but no incorporation of the $\mathrm{D}$-atom into the other neutral fragments. This agrees with the behaviour of deuterated ions $a$ derived from $1 a$ and $2 \mathbf{a}$ by EI. Again, the deuteronated $m$-methoxymethylbenzaldehyde, 4 , prefers elimination of $\mathrm{CH}_{3} \mathrm{OD}$ while the deuteronated para-isomers eliminate mostly $\mathrm{CH}_{3} \mathrm{OH}$. This close analogy shows that the fragmentation of these CI-ions occurs also via intermediate ion/ molecule complexes.

\section{CONCLUSION}

Ions $a_{p}$ and $a_{m}$ with the structure of para- and meta-substituted benzaldehydes protonated at the carbonyl group are easily generated from the corresponding 1-phenylethanols by electron impact. Metastable $a_{p}$ and $a_{m}$ react further by elimination of $\mathrm{CH}_{3} \mathrm{OH}$, loss of $\mathrm{HCOOCH}_{3}$ and formation of ions $\mathrm{CH}_{2}=\mathrm{O}-\mathrm{CH}_{3}$ from the side chain. This latter process as well as the loss of $\mathrm{CH}_{3} \mathrm{OH}$ from ions $a$ can be explained by a more or less 'conventional' fragmentation mechanism which starts by a migration of the proton at the carbonyl group onto the benzene ring. Indeed, this migration by a 'ring walk mechanism' via a $\sigma$-complex can be proven by a H/D-exchange in appropriately labelled ions $a$ before the elimination of methanol. However, the exchange between the proton at the carbonyl group and the four hydrogen atoms at the benzene ring is not complete, and the incorporation of the proton originally at the carbonyl group into the methanol lost is favoured especially in the case of the meta-substituted ions $a_{m}$. Thus, migration of the proton at the carbonyl group occurs also across the benzene ring to the methoxy group by a $\pi$-complex without any exchange between the migrating proton with the other hydrogen atoms. Since the PA of the benzene ring $\left(\mathrm{PA}\left(\mathrm{C}_{6} \mathrm{H}_{6}\right)=759 \mathrm{~kJ} /\right.$ mol; $\left.{ }^{20} \mathrm{PA}\left(\mathrm{CH}_{3}-\mathrm{C}_{6} \mathrm{H}_{5}\right)=794 \mathrm{~kJ} / \mathrm{mol}^{20}\right)$ is less than that of a keto group $\left(\mathrm{PA}\left(\mathrm{CH}_{3}-\mathrm{C}_{6} \mathrm{H}_{4}-\mathrm{CHO}\right)=\right.$ $\left.852 \mathrm{~kJ} / \mathrm{mol} ;{ }^{20} \operatorname{PA}\left(\left(\mathrm{C}_{2} \mathrm{H}_{5}\right)_{2} \mathrm{CO}\right)=843 \mathrm{~kJ} / \mathrm{mol}^{20}\right)$, the transfer of the proton from the carbonyl group to the aromatic ring takes place only in excited ions $a$. It seems possible that this favours the formation of $\pi$-complexes over that of $\sigma$-complexes.

The most interesting reaction of ions $a_{p}$ and $a_{m}$ is the elimination of $\mathrm{HCOOCH}_{3}$, which is formed by a functional group interaction of the two side chains of ions $a$. These side chains are too far apart for a direct 'through space' interaction, and skeletal isomerizations of ions $a_{p}$ and $a_{m}$ into the ortho-isomers can be excluded by the results from deuterated ions $a$. Thus, the formyl substituent has to migrate to the methoxymethyl side chain via an intermediate ion/neutral complex. Obviously, some of the $\pi$ complexes formed by the transfer of the proton at the carbonyl group to the $\pi$-cloud of the benzene ring collapse by protolysis of the $\mathrm{C}-\mathrm{C}$ bond between benzene ring and formyl group into an ion/neutral complex between a formyl cation and a benzylmethylether molecule. The heat of formation of an ion/neutral complex is determined by the sum of the heats of formation of the constituents and the attractive forces between them. $\Delta H_{\mathrm{f}}\left(\mathrm{H}^{+}\right)=1528 \mathrm{~kJ} /$ $\mathrm{mol}^{20 \mathrm{~b}}$ is much larger than $\Delta H_{\mathrm{f}}\left(\mathrm{CHO}^{+}\right)=815 \mathrm{~kJ} / \mathrm{mol}$ or any other organic cation, and the isomerization of a $\pi$-complex of a substituted benzene into an ion/benzene complex is therefore an exothermic reaction. This explains the large tendency of protonated aromatic molecules to form ion/neutral complexes as intermediates during their fragmentations. Indeed our results show that formyl cation/ benzylmethylether complexes are also formed in the $\mathrm{CI}\left(\mathrm{CH}_{4}\right)$ mass spectra of methoxymethylbenzaldehydes.

\section{EXPERIMENTAL}

\section{Mass spectrometry}

The $70 \mathrm{eV}$ EI mass spectra were measured with a MAT 311A mass spectrometer under the following experimental conditions: electron energy $70 \mathrm{eV}$, emitter current $3 \mathrm{~mA}$, acceleration voltage $3 \mathrm{kV}$, ion source temperature $180^{\circ} \mathrm{C}$.

The investigations of metastable ions were performed with a double focusing mass spectrometer VG $\mathrm{ZAB}-2 \mathrm{~F}$ equipped with a combined $\mathrm{EI} / \mathrm{CI}$ ion source using the following experimental conditions:

EI: electron energy $70 \mathrm{eV}$; electron trap current, $50 \mu \mathrm{A}$; ion source temperature $180^{\circ} \mathrm{C}$, accelerating voltage $6 \mathrm{kV}$.

$\mathrm{CI}$ : reagent gas $\mathrm{CH}_{4}, \mathrm{CD}_{4}$; electron energy $100 \mathrm{eV}$; electron emission current $100 \mu \mathrm{A}$; ion source temperature $180^{\circ} \mathrm{C}$; accelerating voltage $6 \mathrm{kV}$.

The reactions of metastable ions in the 2 nd FFR of the VG ZAB-2F instrument were studied by focusing the relevant ion into the 2 nd FFR and varying the electrostatic field. CA/MIKE spectra were obtained by introducing $\mathrm{He}$ into the collision chamber of the 2nd FFR until the intensity of the main beam was reduced to $30 \%$.

\section{Compounds}

4-Methoxymethylbenzaldehyde and 3-methoxybenzaldehyde were obtained as described in the literature. $^{21,22}$

1-(4-Methoxymethylphenyl)-ethanol 1 and 1-(3methoxymethylphenyl)-ethanol 2 were prepared from the corresponding 1-(3-chloromethylphenyl)-ethanol and 1-(4-chloromethylphenyl)-ethanol ${ }^{23}$ by treatment with $\mathrm{CH}_{3} \mathrm{ONa}$ in $\mathrm{CH}_{3} \mathrm{OH}$.

The hydrogen atom of the hydroxyl-group in $\mathbf{1}$ and 2 was exchanged by addition of excess $\mathrm{D}_{2} \mathrm{O}$ to yield $1 \mathrm{a}$ and $\mathbf{2 a}$.

The synthesis of 1-(4-methoxymethylphenyl)- $\mathrm{D}_{1}$ ethanol $1 b$ starts with 4-bromomethylacetophenon, 
which was prepared from 4-methylacetophenone with NBS in $\mathrm{CCl}_{4}$ as described in the literature. ${ }^{24}$ The reduction with $\mathrm{LiAlD}_{4}$ at $-50^{\circ} \mathrm{C}$ in THF followed by substitution with $\mathrm{CH}_{3} \mathrm{ONa}$ in $\mathrm{CH}_{3} \mathrm{OH}$ yielded $\mathbf{1 b}$.

1-(3-Methoxymethylphenyl)- $\mathrm{D}_{1}$-ethanol $\mathbf{2 b}$ was synthesized by the same procedure as $\mathbf{1 b}$ starting from 3-bromomethylacetophenone.

1-(4-Methoxymethyl- $\mathrm{D}_{2}$-phenyl- $\mathrm{D}_{4}$ )-ethanol $1 \mathrm{c}$ has been synthesized from $D_{8}$-toluene which was acetylated with $\mathrm{CH}_{3} \mathrm{COCl}$ and $\mathrm{AlCl}_{3}$ in dry $\mathrm{CS}_{2}$ to yield $\mathrm{D}_{7}$-4-methylacetophenone. This was brominated with NBS, reduced with $\mathrm{LiAlH}_{4}$ and substituted with $\mathrm{CH}_{3} \mathrm{ONa}$ in $\mathrm{CH}_{3} \mathrm{OH}$ according to the procedure for 1 b.

1-(4-Methoxymethyl- $\mathrm{D}_{2}$-phenyl)-ethanol 1e was ob- tained by addition of acetaldehyde to the Grignardcompound from 4-bromo-methoxymethyl- $\mathrm{D}_{2}$-benzene and $\mathrm{Mg}^{25,26}$ in THF. The bromo benzene derivative was obtained by reduction of 4-bromobenzoic acid methyl ester with $\mathrm{LiAlD}_{4}$, followed by reaction with $\mathrm{PBr}_{3}$ and the final substitution with $\mathrm{CH}_{3} \mathrm{ONa}$.

1-(4- $\mathrm{D}_{3}$-Methoxymethylphenyl)-ethanol 1d was prepared from 1-(4-Chloromethylphenyl)-ethanol ${ }^{23}$ by treatment with $\mathrm{CD}_{3} \mathrm{ONa}$ in $\mathrm{CD}_{3} \mathrm{OD}$.

\section{Acknowledgement}

We thank the Deutsche Forschungsgemeinschaft and the Fonds der Chemischen Industrie for financial support of this work. The technical assistance of the mass spectrometric measurements by $\mathrm{Mr}$. E. Gärtner is gratefully acknowledged.

\section{REFERENCES}

1. P. Longevialle and R. Botter, J. Chem. Soc., Chem. Commun. 1980, 823.

2. T. H. Morton, Tetrahedron 38, 3195 (1983).

3. (a) T. Su and M. T. Bowers in Gas Phase lon Chemistry, ed. by M. T. Bowers, Vol. 1; Academic Press, New York (1979). (b) T. F. Magnera and P. Kebarle in lonic Processes in the Gas Phase ed. by M. A. Almoster-Ferreira; NATO ASI series C, D. Reidel Publ. Comp., Dordrecht, Boston, Lancaster, (1984).

4. P. Vogel, 'Carbocation Chemistry' (Studies in Organic Chemistry, Vol. 21), Elsevier, Amsterdam, (1985).

5. (a) D. H. Williams, B. J. Stapleton and R. D. Bowen, Tetrahedron Lett. 1978, 2919. (b) R. D. Bowen and D. H. Williams, J. Am. Chem. Soc. 100, 7454 (1978). (c) R. D. Bowen, J. Chem. Soc., Perkin Trans. II, 1980, 1219. (d) J. F. Wendelboe, R. D. Bowen and D. H. Williams, J. Chem. Soc., Perkin Trans. II, 1981, 959.

6. R. G. Cooks, J. H. Beynon, R. M. Caprioli and G. R. Lester; Metastable lons, Elsevier, New York, (1973).

7. G. C. Stafford, Jr., P. E. Kelley, J. E. P. Syka, W. E. Reynolds and J. F. J. Todd, Int. J. Mass Spectrom. Ion Processes 60, 85 (1984).

8. K. P. Wanczek, Int. J. Mass Spectrom. Ion Processes 60, 11 (1984).

9. F. W. McLafferty (Ed.), Tandem Mass Spectrometry, Wiley, New York, (1983).

10. (a) D. Kuck, W. Bäther and H. F. Grützmacher, J. Am. Chem. Soc. 101, 7154 (1979). (b) W. Bäther, D. Kuck and H. F. Grützmacher, Org. Mass Spectrom. 20, 572 (1985). (c) W. Bäther and H. F. Grützmacher, Int. J. Mass Spectrom. Ion Processes, 64, 193 (1985).

11. U. Filges, Diplomarbeit, Universität Bielefeld, 1984.

12. These investigations have been performed with the advanced Research Ion Trap-System of Finnigan MAT. We thank P. E. Kelley, Finnigan MAT Corp., San José, Ca., U.S.A., and Dr. R. Schubert, Finnigan MAT, Bremen, Germany, for these measurements.

13. Similar effects on the elimination of $\mathrm{CH}_{3} \mathrm{OH} / \mathrm{CH}_{3} \mathrm{OD}$ have been observed during the reactions of other deuterated and protonated aromatic ketones.

14. Results by G. Prior and D. Kuck of this laboratory, to be published.

15. The loss of fragments corresponding to (HCOX) with $\mathrm{X}=\mathrm{Cl}, \mathrm{Br}, \mathrm{OH}$, has also been observed from appropriately substituted analogues of ions $a{ }^{11}$ The relative abundance of this fragmentation depends much on the aromatic system involved and is the main reaction for phenathrene and diphenyl compounds (U. Filges and H. F. Grützmacher, to be published).

16. (a) C. J. Cassady, B. S. Freiser and D. H. Russell, Org. Mass Spectrom. 18, 378 (1983). (b) D. H. Russell, B. S. Freiser, E. H. McBay and D. C. Canada, Org. Mass Spectrom. 18, 474 (1983).

17. (a) F. Cacace, J. Chem. Soc., Perkin Trans. II 1982, 1129. (b) N. Pepe and M. Speranza, J. Chem. Soc., Perkin Trans. II, $1981,1430$.

18. J. L. Beauchamp and R. C. Dunbar, J. Am. Chem. Soc. 92 $1477(1970)$

19. R. van Dorn and N. M. M. Nibbering, Org. Mass Spectrom. 13, 527 (1978).

20. (a) S. G. Lias, J. F. Liebman and R. D. Levin, J. Phys. Chem. Ref. Data 13, 695 (1984). (b) H. M. Rosenstock, K. Draxl, B. W. Steiner and J. T. Herron, J. Phys. Chem. Ref. Data 6, Suppl. 1 (1977).

21. G. Arditti and L. Palfray, Acad. Sci., Compt. Rend., 223, 635 (1946).

22. J. W. Baker, J. A. L. Brieux and D. G. Saunders, J. Chem. Soc., 404 (1956).

23. G. L. Arcus and N. S. Solomons, J. Chem. Soc., 1515 (1962).

24. B. P. Jarvis and J. C. Saukaitis, J. Am. Chem. Soc. 95, 7708 (1973).

25. R. Herrmann and H. Schwarz, Z. Naturforsch. 31B, 870-875 (1976).

26. R. C. Fuson and B. Freedman, J. Org. Chem. 23, 1161 (1958). 